\title{
Surface modification of poly(L-lactide) and polycaprolactone bioresorbable polymers using RF plasma discharge with sputter deposition of a hydroxyapatite target
}

\author{
E.N. Bolbasov ${ }^{\mathrm{a}}$, M. Rybachuk ${ }^{\mathrm{b}}$, A.S. Golovkin ${ }^{\mathrm{c}}$, L.V. Antonova ${ }^{\mathrm{c}}$, E.V. Shesterikov ${ }^{\mathrm{a}}$, \\ A.I. Malchikhina ${ }^{a}$, V.A. Novikov ${ }^{\mathrm{d}}$, Y.G. Anissimov ${ }^{\mathrm{e}}$, S.I. Tverdokhlebov ${ }^{\mathrm{a}, *}$ \\ a Tomsk Polytechnic University, 30 Lenin Avenue, Tomsk 634050, Russian Federation \\ b Griffith University, School of Engineering, Engineering Dr., Southport, QLD 4222, Australia \\ ${ }^{\mathrm{c}}$ Kuzbass Cardiology Centre-Research Institute for Cardiovascular Diseases, Russian Academy of Medical Sciences (Siberian Branch), 6 Sosnovy Blvd, \\ Kemerovo 650002, Russian Federation \\ ${ }^{\mathrm{d}}$ Tomsk State University, 36 Lenin Avenue, Tomsk 634050, Russian Federation

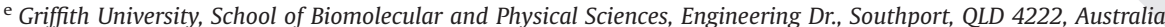

\section{A R T I C L E I N F O}

Article history:

Received 20 May 2014

Accepted 18 June 2014

\section{Keywords:}

Polymers

Biomaterials

Magnetron sputter deposition

Calcium-phosphate

\begin{abstract}
A B S T R A C T
Surface modification of poly(L lactide) (L-PLA) and polycaprolactone (PCL) bioresorbable polymers by radio-frequency thermal glow discharge plasma is reported. Improved biocompatibility of L-PLA and PCL materials was obtained by employing hydroxyapatite target sputtering in $\mathrm{Ar}^{+}$plasma as evidenced by the change of L-PLA and PCL properties from highly hydrophobic to hydrophilic, with absolute wettability obtained for both materials, and enhanced cell line EA-hy 926 attachment to modified surfaces. Surface roughness and surface free energy were found to increase significantly for both polymers under prolonged plasma exposure and, a longer chain aliphatic PCL were found to display a marginally better post plasma-treated biocompatibility compared to L-PLA.
\end{abstract}

(c) 2014 Published by Elsevier B.V.

\section{Introduction}

Applications of biodegradable materials such as poly(L-lactide) $\left(\mathrm{C}_{3} \mathrm{H}_{4} \mathrm{O}_{2}\right) n$ (L-PLA) and polycaprolactone $\left(\mathrm{C}_{6} \mathrm{H}_{10} \mathrm{O}_{2}\right)_{n}(\mathrm{PCL})$ in an environment where attachment and proliferation of living cells is important necessitate specific surface properties, namely, the surface roughness, to be within tens of nm (normally in 20$80 \mathrm{~nm}$ range and tailored to a specific cell line) and to be highly hydrophilic [1]. Although surface topology and physio-chemical properties have a major influence on the attachment of cells determining cell polarisation, cell morphology, spatial orientation of cell's cytoskeleton components, the degree of order of intracellular transport and many other important parameters [2]. Recent experimental findings indicate that plasma surface treatment of L-PLA and PCL polymers increases surface roughness and reduces surface free energy and improves attachment of various biological cells on the surface [3]. However, despite a range of plasma treatment methods available (i.e. thermal and non-thermal plasma corona discharge, dielectric barrier discharge, etc.) inherent hydrophobicity and high surface-free energy properties of L-PLA and PCL

\footnotetext{
* Corresponding author. Tel: +7 3822563437.

E-mail address: tverd@tpu.ru (S.I. Tverdokhlebov).
}

are still poorly mend able in a controlled manner and hinder many applications [4,5]. While non-thermal plasma surface treatments are preferred for simplicity, modification of L-PLA and PCL under thermal plasma conditions remains less popular owing to inherent difficulties associated with identifying appropriate plasma conditions and complimenting target material(s) for a specific (bio)material surface treatment.

In this Letter we report a pilot study on the effects of treatment of L-PLA and PCL polymers by a radio-frequency (RF) glow discharge plasma operated under $\mathrm{Ar}^{+}$target sputtering mode to reduce hydrophobicity and surface-free energy towards improving living cell affinity. Hydroxyapatite $(\mathrm{HA}) \mathrm{Ca}_{5}\left(\mathrm{PO}_{4}\right)_{3}(\mathrm{OH})$ was selected as a sputter target owing to HA natural (bio)-compatibility and ability to facilitate biological functions of various implant materials by plasma sputtering processes [6-8]. A dielectric HA serves as an ideal target material for an RF excited, plasma-assisted, sputtering of L-PLA and PCL to form a (bio-)ceramic/(bio-)resorbable polymer interface in support of live cell attachment studies.

\section{Materials and methods}

PURASORB ${ }^{\circledR}$ PL65 (Corbion Purac) with inherent viscosity (IV) at midpoint $\mathrm{IV}_{\mathrm{L}-\mathrm{PLA}}=6.5 \mathrm{dL} / \mathrm{g}$, and Policaprolactone PURASORB ${ }^{\circledR}$ 
PC12 $\mathrm{IV}_{\mathrm{PCL}}=1.2 \mathrm{dL} / \mathrm{g}$ (Corbion Purac) were used as precursors to prepare a $4 \%$ solution of L-PLA and PCL polymers, respectively, in dichloromethane $\mathrm{CH}_{2} \mathrm{Cl}_{2}$ (DCM) (Panreac Química S.L.U.). A 4\% polymer solution of $12( \pm 1) \mathrm{g}$ was casted at room temperature (RT) into a glass vial to solidify. After $24 \mathrm{~h}$ when most of DCM was vaporized, the polymer films were removed using Milli- $Q$ water, followed by air-drying at $35{ }^{\circ} \mathrm{C}$ for $24 \mathrm{~h}$. As-prepared L-PLA and PCL polymer films were treated in an RF glow discharge plasma following the recent work Tverdokhlebov et al. [9]. In addition the specific RF power was set to $5 \mathrm{~W} / \mathrm{cm}^{2}$ to maintain electron density within $\sim 10^{9}-10^{10} \mathrm{pp} \mathrm{cm^{3 }}$ range and target-to-substrate distance was extended to $16 \mathrm{~cm}$ to facilitate enhanced coagulation of elemental plasma and target species under collision plasma conditions. Film exposure to plasma was 30, 60 and $150 \mathrm{~s}$.

Film surface topology was studied using atomic force microscopy (AFM) (Solver-HV, NT-MDT) in air at RT under the tapping mode; Gwyddion 2.25 package was used to estimate root mean square values of surface roughness, $R_{m s}$. Wetting tests were performed with glycerol and Milli- $Q$ water using a contact angle goniometer (Easy Drop, KRÜSS GmbH); the surface free energy, $\gamma$, was estimated using OWRK method [10]. Cell line EA-hy 926 provided by Cora-Jean S. Edgell, (University of North Carolina, USA) were used in cell affinity studies with cells cultured for $72 \mathrm{~h}$ employing the protocol described in Ref. [11]. The EA-hy 926 cells were labelled using fluorescent cell linker dye PKH26 (SigmaAldrich) and bis-Benzimide $\mathrm{H} 33342$ trihydrochloride nucleic acid stain (Sigma-Aldrich).

\section{Results and discussions}

Figs. 1 and 2 show the results of surface topology studies for stock L-PLA and PCL samples (see Fig. 1a for L-PLA, Fig. 2a for PCL), and for plasma-modified samples (see Fig. 1b-d for L-PLA, Fig. 2b-d for PCL); AFM topographic images, 2D fluorescent map of labelled EA-hy 926 cells; wettability images L-PLA and PCL with $\mathrm{H}_{2} \mathrm{O}$ and

a
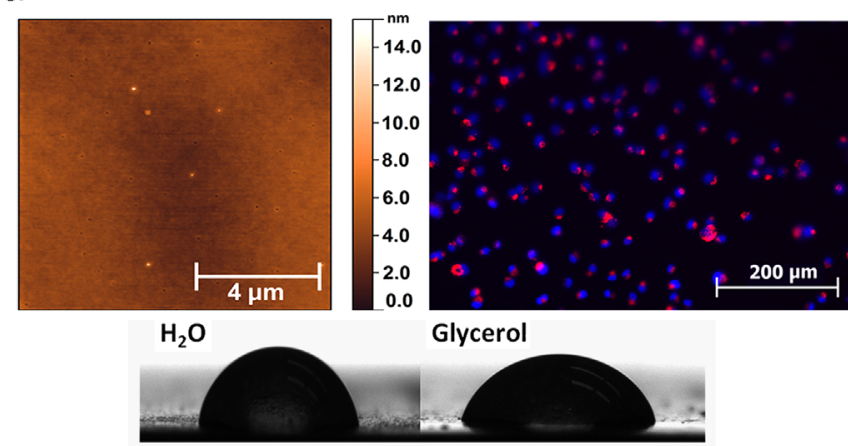

C
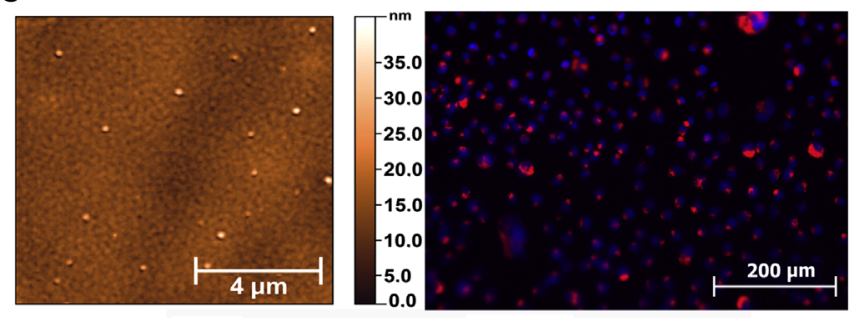

$\mathrm{H}_{2} \mathrm{O}$ Glycerol

glycerol droplets. A summary of topological features for stock and plasma-treated L-PLA and PCL is given in Table 1 , where changes for $R_{m s}$, contact angles of water, $\theta_{\mathrm{H}_{2} \mathrm{O}}$, and glycerol, $\theta_{g l}$, surface free energy, $\gamma$, including apolar, $\gamma^{L W}$, component accounting for Liftshitz/ van der Waals (LW) type interactions, polar, $\gamma^{A B}$, component accounting for acid-base $(\mathrm{AB})$ or donor-acceptor type interactions and total cell population are displayed as a function of the exposure time, $t$.

The obtained results indicate that the measured values for surface roughness gradually increase to a maximum of $\sim 30 \mathrm{~nm}$ for L-PLA and $\sim 70 \mathrm{~nm}$ for PCL with plasma exposure due to thermochemical degradation of the polymeric material mostly caused by increased presence of free $\mathrm{H}$ - bonds and plasma and target species bombardment. The latter are reactive, positively charged $\mathrm{CaO}^{+}$, $\mathrm{Ca}^{2+}, \mathrm{PHO}^{+}, \mathrm{PO}^{+}, \mathrm{P}^{+}$and negative charged $\left(\mathrm{PO}_{4}^{-}\right)_{3}$ species sputtered out from the HA target which are attracted by the surface of L-PLA and PCL. The result of these interactions is the formation of an amorphous calcium aliphatic compound with significantly altered populations of carbonyl $(-\mathrm{C}=\mathrm{O})$, hydroxyl $(-\mathrm{OH})$ functional groups and, calcium-phosphate pre-nucleation layer on L-PLA and PCL materials. Earlier, Boyd et al. confirmed the formation of the amorphous phase developing at film growth stages for HA sputtering on metal substrates [12].

We postulate that these processes occur simultaneously resulting in the formation of an amorphous (bio-)ceramic/(bio-)resorbable polymer interface such as $a-\mathrm{Ca}-(\mathrm{L}-\mathrm{PLA})-\mathrm{O}_{3}$ on L-PLA, and $a-$ $\mathrm{Ca}-(\mathrm{PCL})-\mathrm{O}_{3}$ on PCL material. Plasma treatment of both L-PLA and PCL materials gradually change their surface properties from hydrophobic, with surface energy values of $\sim 20 \mathrm{~mJ} / \mathrm{m}^{2}$ for L-PLA and $\sim 30 \mathrm{~mJ} / \mathrm{m}^{2}$ for PCL to largely hydrophilic, with a maximum values of $\gamma$ of $\sim 73 \mathrm{~mJ} / \mathrm{m}^{2}$ reported for both materials indicating absolute wettability. It is established that surface free energy of hydrocarbons $\mathrm{C}_{n} \mathrm{H}_{2 n-2}$ is strongly related to $\mathrm{C}$ - saturation, therefore the increase of hydrophilic properties in L-PLA and PCL materials is be attributed to strong de-hydrogenation process occurring during the plasma treatment.

b

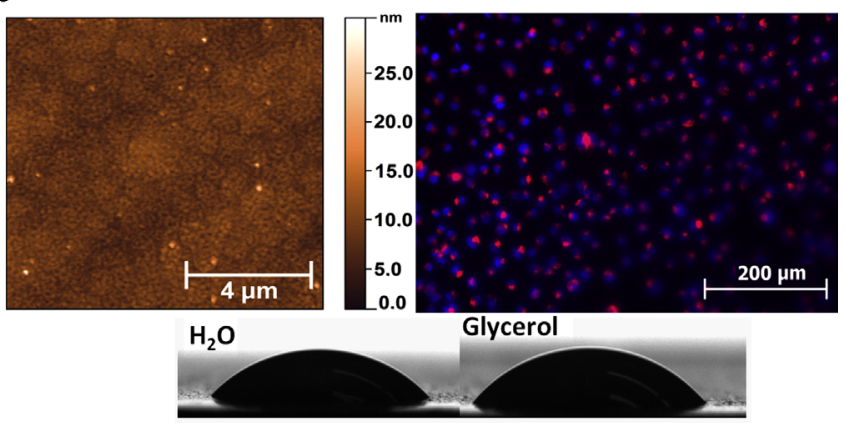

d

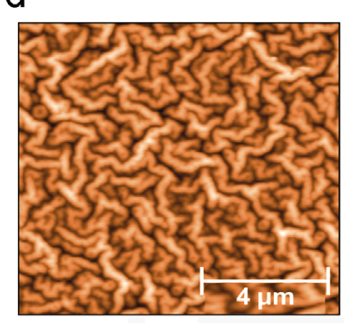

$\mathrm{H}_{2} \mathrm{O}$

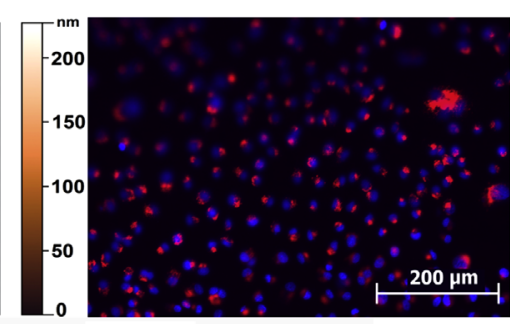

Glycerol
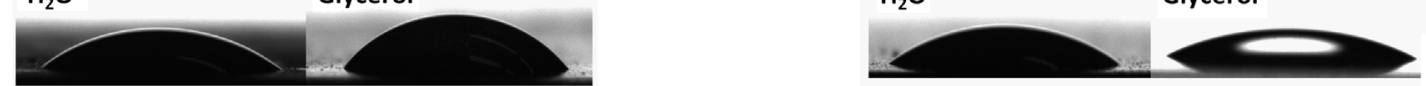

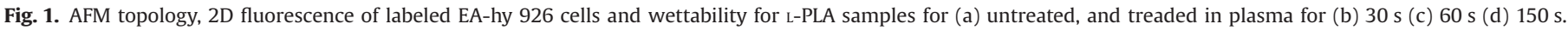


a

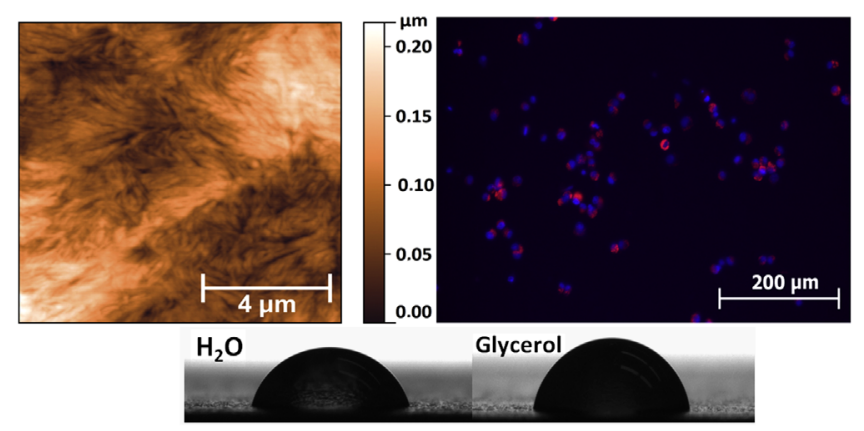

C
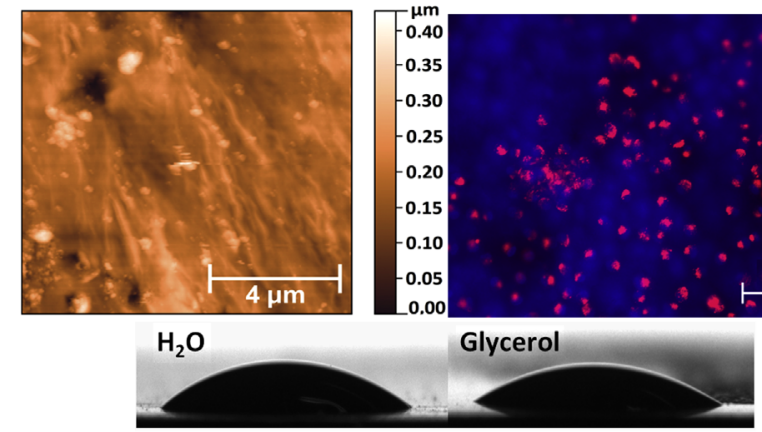

b

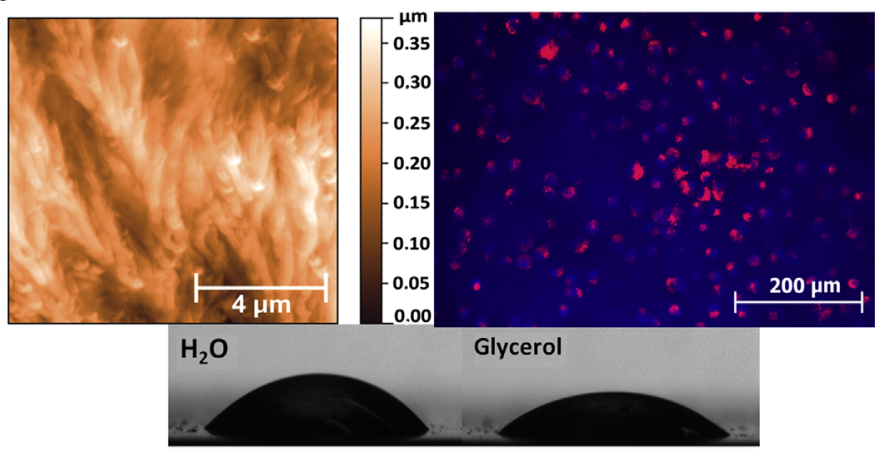

d

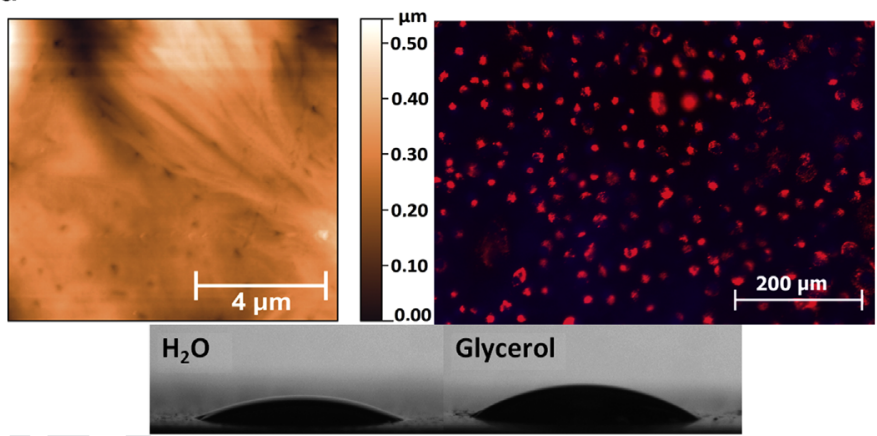

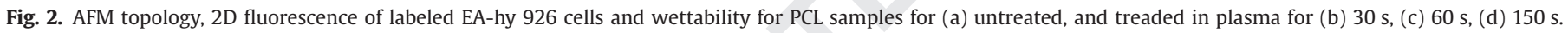

Table 1

Surface roughness, contact angle, surface free energy and total cell population values for stock (untreated) and samples treated in plasma for 30,60 and 150 s.

\begin{tabular}{|c|c|c|c|c|c|c|c|}
\hline \multirow[t]{2}{*}{ Plasma exposure time, $t(\mathrm{~s})$} & \multirow[t]{2}{*}{ Surface roughness, $R_{m s}(\mathrm{~nm})$} & \multicolumn{2}{|c|}{ Contact angle } & \multicolumn{3}{|c|}{ Surface free energy } & \multirow{2}{*}{$\frac{\text { Cell population }}{M E(25 \%, 75 \%)}$} \\
\hline & & $\theta_{\mathrm{H}_{2} \mathrm{O}}$, deg & $\theta_{g l}$, deg & $\gamma, \mathrm{mJ} / \mathrm{m}^{2}$ & $\gamma^{L W}, \mathrm{~mJ} / \mathrm{m}^{2}$ & $\gamma^{A B}, \mathrm{~mJ} / \mathrm{m}^{2}$ & \\
\hline \multicolumn{8}{|l|}{ Poly(L-lactide) (L-PLA) } \\
\hline Untreated & $\leq 5$ & $88 \pm 7$ & $84 \pm 6$ & $20 \pm 5$ & $8 \pm 2$ & $12 \pm 2$ & $409(310 ; 471)$ \\
\hline 30 & $\leq 5$ & $46 \pm 3$ & $45 \pm 5$ & $52 \pm 3$ & $13 \pm 2$ & $40 \pm 2$ & $775(711 ; 823)$ \\
\hline 60 & $\leq 5$ & $34 \pm 3$ & $42 \pm 2$ & $65 \pm 2$ & $7 \pm 1$ & $58 \pm 1$ & $741(696 ; 828)$ \\
\hline 150 & $30 \pm 5$ & $24 \pm 4$ & $38 \pm 2$ & $\leq 73$ & $6 \pm 1$ & $67 \pm 2$ & $624(487 ; 738)$ \\
\hline \multicolumn{8}{|l|}{ Polycaprolactone (PCL) } \\
\hline Untreated & $40 \pm 5$ & $77 \pm 5$ & $85 \pm 3$ & $33 \pm 2$ & $\leq 5$ & $32 \pm 2$ & $242(174 ; 300)$ \\
\hline 30 & $45 \pm 5$ & $42 \pm 3$ & $47 \pm 3$ & $56 \pm 4$ & $12 \pm 3$ & $45 \pm 2$ & $417(254 ; 694)$ \\
\hline 60 & $55 \pm 5$ & $35 \pm 4$ & $40 \pm 6$ & $63 \pm 4$ & $9 \pm 2$ & $53 \pm 2$ & $501(286 ; 669)$ \\
\hline 150 & $70 \pm 5$ & $13 \pm 3$ & $25 \pm 4$ & $\leq 73$ & $11 \pm 2$ & $62 \pm 4$ & $715(663 ; 760)$ \\
\hline
\end{tabular}

Moreover, since amorphous solids traditionally exhibit lower surface energy values than crystalline counterparts, we postulate that L-PLA and PCL surface properties undergo marked transition from an amorphous to a crystalline state further supporting the probability of formation of a (bio-)ceramic/(bio-)resorbable polymer interface. The marked increase of $\gamma^{A B}$ values for both materials reveals that plasma treatment promotes high intermolecular force interactions on the surface and have a minor, insignificant, effect on apolar surface properties of L-PLA and PCL materials.

The latter is evidenced by minimal changes of $\gamma^{L W}$ component. The reasons are twofold: one is the presence of local reactive molecular domains participating in radical formation, molecular cross-linking and/or $\mathrm{C}=$ bond formations on polymer surface under plasma irradiation, the other are the interactions with the positive (and neutral) species from the HA target noted earlier. High intermolecular force interactions on plasma treated L-PLA and PCL contribute towards the increase of $\mathrm{C}-\mathrm{O}$ and $\mathrm{O}-\mathrm{C}=\mathrm{O}$ functional groups with additional $\mathrm{O}$ - ions supplied by the sacrificial HA target.

We attribute a major increase of surface roughness in PCL relative to L-PLA to inherent differences in their molecular structure: L-PLA while lacking a longer $\mathrm{C}=\mathrm{C}$ backbone is less predisposed to severe thermal and physio-chemical modifications than PCL counterpart, and as PCL exhibits lower solubility, it is naturally more prone to molecular crosslinking during processing. PCL therefore displays more uneven surface with the most pronounced (i.e. higher value) $R_{m s}$ under plasma treatment.

Living cell culture experimental the data are presented in Table 1. It shows an increased affinity of EA-hy 926 cell attachment to plasma modified surfaces and retrospectively indicates that the increase of surface roughness and modification of surface functional groups is beneficial to overall cell viability. Notably, a longer chain aliphatic PCL polymer was found to display a marginally better post plasma-treated biocompatibility compared to shorterchain L-PLA. 


\section{Conclusion}

In summary, we have shown that surface properties of L-PLA and PCL bioresorbable polymers can be successfully modified employing thermal glow discharge plasma sputtering hydroxyapatite target. Surface roughness, surface free energy could be altered by plasma treatment to achieve maximum wettability of L-PLA and PCL materials enhancing permanent cell line EA-hy 926 attachment. We postulate the formation of a (bio-)ceramic/(bio-) resorbable polymer interface as the result of plasma-surface interaction and suggest that the reported complimentary (bio-) target sputtering approach is not exclusive to L-PLA and PCL polymers, but can aid in modification of other bioresorbable materials.

\section{Acknowledgments}

This work was financially supported by the Russian Foundation for Basic Research (projects \#13-08-98052; \#13-08-90743); Federal Target Program (state contract \# 14.577.21.0036). M.R. acknowledges Griffith for lectureship program and start-up funding.

\section{References}

[1] Tian H, Tang Z, Zhuang X, Chen X, Jing X. Biodegradable synthetic polymers: preparation, fictionalization and biomedical application. Prog Polym Sci 2012;37:237-80

[2] Bauer S, Schmuki P, Mark K, Park J. Engineering biocompatible implant surfaces: Part I: Materials and surfaces. Prog Mater Sci 2013;58:261-326.
[3] Morent R, De Geyter N, Desmet T, Dubruel P, Leys C. Plasma surface modification of biodegradable polymers: a review. Plasma Process Polym 2011;8:171-90.

[4] Rasal RM, Janorkar AV, Hirt DE. Poly(lactic acid) modifications. Prog Polym Sci 2010;35:338-56

[5] Woodruff MA, Hutmacher DW. The return of a forgotten polymer-Polycaprolactone in the 21st century. Prog Polym Sci 2010;35:1217-56.

[6] Paital SR, Dahotre NB. Calcium phosphate coatings for bio-implant applications: materials, performance factors, and methodologies. Mater Sci Eng: $\mathrm{R}$ 2009;66:1-70.

[7] Wang H, Eliaz N, Hobbs LW. The nanostructure of an electrochemically deposited hydroxyapatite coating. Mater Lett 2011;65:2455-7.

[8] Podporska-Carroll J, Quilty B, Devery R. Non-cytotoxic and antimicrobial plasma sprayed coatings for orthopaedic application. Mater Lett 2013;112:54-7.

[9] Tverdokhlebov SI, Bolbasov EN, Shesterikov EV, Malchikhina AI, Novikov VA Anissimov YG. Research of the surface properties of the thermoplastic copolymer of vinilidene fluoride and tetrafluoroethylene modified with radio-frequency magnetron sputtering for medical application. Appl Surf Sci 2012;263:187-94.

[10] Owens DK, Wendt RC. Estimation of the surface free energy of polymers. J Appl Polym Sci 1969;13:1741-7.

[11] Emeis JJ, Edgell CJ. Fibrinolytic properties of a human endothelial hybrid cell line (Ea.hy 926). Blood 1988;71:1669-75.

[12] Boyd AR, O'Kane C, Meenan BJ. Control of calcium phosphate thin film stoichiometry using multi-target sputter deposition. Surf Coat Technol 2013;233:131-9. 